\title{
El Estado-Padrino: Caciquismo y redes caciquiles en Andalucía oriental durante la Restauración
}

\author{
Ma DOLORES RAMOS
}

Acepté convencida de que este encuentro era necesario para revisar conceptual y metodológicamente el tema del caciquismo. Ya desde el primer momento me pareció indicativo que el título del congreso enlazara de manera consciente los sustantivos Caciquismo y República, sobre todo porque el primero de ellos había sido asociado de manera casi exclusiva con el sistema de la Restauración, como si lo sucedido en tan dilatado periodo no hubiera tenido antecedentes ni consecuencias. Por ello, y aunque parezca obvio subrayarlo, hay que afirmar que caciquismo hubo antes, durante y después de la Restauración, si bien el mecanismo político del pacto, la alternancia y el encasillado son típicamente canovistas. Desde luego, las redes caciquiles no desaparecieron con la llegada de la República, hecho que explica algunos de los avatares de la agitada década de los treinta.

En este sentido, el congreso sobre "Caciquismo y República" no sólo ha servido para mostrarnos lo hecho -que necesariamente ha de ser revisado- sino también lo mucho que queda por hacer en Andalucía. La ón ha de ser forzosamente plural, habida cuenta de las diferentes formas de entender y construir la historia que tenemos los que nos dedicamos a este oficio. No obstante, para aunar criterios, facilitar el trabajo y tratar de establecer una tipología del caciquismo se vertebraron las ponencias y comunicaciones en torno a un hecho diferencial en el plano políticoinstitucional: el tiempo de la Monarquía y el de la República; el segundo criterio fue de orden geográfico: la existencia de las dos Andalucías, con sus diferencias, semejanzas y matices. Como ocurre siempre, los resultados afloraron a lo largo del congreso y se materializaron en una serie de conclusiones parciales o generales. Esta ponencia-relato está abierta, en su provisionalidad -consecuencia afortunada del avance del conocimiento histórico- a esos resultados, más aún, a las investigaciones futuras, que deseo sean novedosas y abundantes. 


\section{EL CACIQUISMO: NECESIDAD DE UNA REDEFINICION}

Desde una óptica funcionalista, el caciquismo ha sido definido como un sistema de prácticas políticas, electorales y administrativas de carácter fraudulento, entre las cuales alcanzan especial relieve -aunque no siempre se señale con la fuerza que merece- las corruptelas en la administración de justicia. Estas prácticas, presentadas como fruto de la España oficial, propias por tanto de la clase política, no tenían, según sus intérpretes, ninguna relación con la España real, es decir, con los audaces propietarios, capitanes de empresa y honrados trabajadores que consentían más o menos la situación, permanecían indiferentes, o bien mostraban su pasividad ante ellas. El divorcio entre la España real y la oficial posibilitaba que la esfera política quedara al margen de los intereses económicos y que éstos no fueran ía su origen, según esta hipótesis de trabajo, en el atraso cultural y político del país ${ }^{1}$.

Nada más lejos de la realidad. Es preciso darle la vuelta a esta teoría interpretativa. En primer lugar el sistema clientelar sobrepasa el tejido político para instalarse -mejor sería decir enquistarse- en el cuerpo social, de acuerdo con la estructura piramidal de éste. Las corruptelas se interiorizan y reproducen debido a la existencia de unas redes de apoyo y complemento que son causa y efecto a la vez del caciquismo: redes económicas (relaciones subordinadas de producción, grupos de presión, asociaciones patronales), que permiten imbricar el clientelismo en el seno de la lucha de clases desarrollada tanto en las zonas rurales como en las urbanas; redes políticas -sin duda las más conocidas- constituidas

(1) J. TUSELL, Oligarquía y caciquismo en Andalucia (1890-1923). Barcelona, 1976; J. TUSELL, La crisis del caciquismo en Andalucía (1923-1931). Madrid, 1977; J. TUSELL, Sociología electoral de Madrid, 1903-1931. Madrid, 1968, que constituyó la memoria de Licenciatura de su autor y se convirtió en un clásico, metodológicamente hablando, de los estudios electorales; J. TUSELL GOMEZ, El sistema político español en el reinado de Alfonso XIII.En Historia Social de España. S. XX. Madrid, 1976, 63-82. JOSE VARELA ORTEGA, Los amigos políticos. Partidos, elecciones y caciquismo en la Restauración (1875-1900) Madrid, 1977; J. VARELA ORTEGA, Los amigos políticos: funcionamiento del sistema caciquista. Revista de Occidente $n^{2} 127,1973$, 45-74, que constituyó un adelanto del libro anterior; JOAQUIN ROMERO MAURA, El caciquismo: una tentativa de conceptualización. Revista de Occidente $\mathrm{n}^{\circ} 127,1973,15-44$. M. TUÑON DE LARA, Historia y realidad del poder. El poder y las élites en el primer tercio de la España del siglo XX. Madrid, 1967, libro fundamental para comprender el alcance de las redes caciquiles; M. TUÑON DE LARA, Las municipales del sufragio. Tres casos significativos: mayo 1891, noviembre 1917 y febrero 1920. Desintegración del canovismo y ascensión de republicanos y socialistas. Historia $16 \mathrm{n}^{\circ} 24$ (1978), 32-39. OCTAVIO RUIZ MANJONCABEZA, El partido radical, 1908-1936. Madrid, 1976. Ruiz-Manjón en su etapa de catedrático y director de departamento en Granada ha impulsado gran número de trabajos de investigación sobre el tema en la universidad de Granada. Lo mismo ha sucedido con Rafael Sánchez Mantero en Sevilla. 
por "los partidos de notables, el encasillado y las corruptelas electorales integradas plenamente en el sistema de poder; redes culturales, posibilitadas por el analfabetismo real y funcional, por la oposición entre saber letrado e iletrado y por la discriminación de la cultura oral. No hay que olvidar que la sociedad española de los siglos XIX y XX presentaba un grado de violencia estructural considerable, con grandes desequilibrios y contrastes. En este contexto el grito colectivo de cientos de granadinos en febrero de 1919, aquel «iMuera el cacique!, no expresaba en algunas gargantas el deseo de acabar con el caciquismo sino más bien el de defenestrar al cacique enemigo. En una sociedad donde la prepotencia de los grandes propietarios y poderosos en general había generado a su vez la prepotencia de los medianos propietarios -en virtud de un movimiento de arrastre y emulación- unos y otros podían convertirse virtualmente en caciques. En medio de aquella sociedad violenta de grandes, medianos y pequeños señores, caciques y padrinos se generaban de vez en cuando estallidos de protesta como el ocurrido en Benagalbón en $1914^{2}$. En este caso la protesta popular -violenta por definiciónlogróromper el modelo caciquil y varias familias hubieron de pagar una larga condena por ello. $\mathrm{Y}$ es que las redes clientelares, consensuadas en las alturas o en los niveles intermedios, no pueden prescindir la mayoría de las veces de un fuerte grado de violencia implícita o explícita.

El caciquismo es fruto de un sistema de poderes desequilibrado, más evidente en las sociedades rurales que en las urbanas, aunque debido a las particulares características de la formación social española se detecte su implantación y desarrollo en todo el país. Desde luego, como afirman los teóricos que han estudiado el poder (Weber, Mills, Heller, Foucault, entre otros), éste implica aceptación, coacción, sumisión, discrepancias, oposición, violencia, y su ejercicio adopta formas institucionales y fácticas: "gobiernos a la sombra", poderes paralelos y redes de patronazgo. Así, estas redes convertián a Natalio Rivas en el "padrino" de una parte de la Alpujarra granadina, y lo mismo ocurría con Fernández de Córdoba en Loja o con La Chica en la ciudad de Granada. Fuera de juego quedaban otros padrinos o aspirantes a tales. Estas relaciones de protección y dependencia dan pie a otra consideración del caciquismo, de carácter ético, pero al ser éste un tema escasamente tratado sólo podemos hablar por el momento del "buen y del mal padrino", del "buen y del mal cacique". Futuras investigaciones deberían ocuparse de estos aspectos.

La tierra ha sido en Andalucía una expresión de riqueza, de poder y status, un arma utilizada real y simbólicamente por los propietarios con-

(2) Véase al respecto mi artículo, Revuelta popular versus caciquismo: Elecciones y disturbios sociales en Benagalbón. Jábega n 47 (1984), 28-44. 
tra los no propietarios ${ }^{3}$. Sólo hay que recordar la imagen del señorito a caballo y el jornalero a sus pies, ensayando una reverencia, la mirada cabizbaja en señal de respeto y acatamiento. En este marco de desigualdades sociales y de violencia estructural hay que hacerse algunas preguntas. ¿Estádesmovilizado el campesino realmente?. Si saber es poder, hasta dónde puede ser utilizada la propia sabiduría, el conocimiento de tácticas y estrategias de lucha, la cultura iletrada, la tradición oral que habla de solidaridades, batallas ganadas y perdidas en el pasado. El discurso de la sumisión es contestado por el discurso de la rebelión, pero hay que preguntarse cómo, cuándo, dónde y en qué circunstancias se produce lo uno y lo otro. ¿Por qué, por ejemplo, el modelo caciquil se rompe en determinados lugares? ¿Qué podrían aportar la historia de las mentalidades, la antropología social y cultural al estudio del caciquismo, del patronazgo y de las clientelas?

El caciquismo remite, por otra parte, a un sistema de relaciones simbólicas establecidas en torno a la trilogía padre-patrón-padre eterno. En un sistema patriarcal bien definido, el poder -por tanto, también, sus derivaciones caciquiles- adopta, explícitamente, formas masculinas, ya que el papel de las mujeres en la esfera pública es irrelevante y su reino* pertenece a la vida privada. La "mujer pública" ha explicitado su cuerpo, su intimidad, su sexualidad, mientras el hombre público es el hombre del poder. La imagen de un mundo al revés, sugerida por Natalie Zemon Davis, supondría una inversión de ese estado de cosas y el acceso de las mujeres a los puestos de decisión ${ }^{4}$.

Pero el problema de fondo es el de la ciudadanía. Vale la pena extenderse en él debido a la necesidad de incluir esta perspectiva de análisis en los estudios sobre el poder, el caciquismo y el padrinazgo. El concepto de ciudadano libre y dueño de sí mismo -frente al concepto

(3) A.M. BERNAL, La propiedad de la tierra y las luchas agrarias andaluzas. Barcelona, Ariel, 1974. Véase también de este autor El rebaño hambriento en la tierra feraz. Historia de Andalucía VII. La Andalucia Contemporänea (1868-1981). Madrid-Barcelona, Cupsa-Planeta, 1981, págs. 65-99. J.L. DELGADO (ed.), La cuestión agraria en la España contemporánea. VI Coloquio de Pau. Madrid, Edicusa, 1976. E. MALEFAKIS Reforma agraria y revolución campesina en la España del siglo XX. Barcelona, Ariel, 1971. J. MAURICE, La reforma agraria en España en el siglo XX (1900-1936). Madrid, Siglo XXI, 1978. El anarquismo andaluz. Campesinos y sindicalistas, (1868-1936). Barcelona, Crítica, 1990. D. PAZOS Y GARCIA, Politica social agraria de España (Problemas, situación y reformas). Madrid, Establecimiento Tipográfico Jaime Ratés, 1920. P. CARRION, Los latifundios en España. Su importancia. Origen. Consecuencias y solución. $2^{2}$ ed., Barcelona, Ariel, 1975. CH. MIGNON, Campos y campesinos de la Andalucía mediterránea. Madrid, Servicio de Publicaciones Agrarias, 1987.

(4) N. ZENON DAVIS, Un mundo al revés: las mujeres al poder. En: J.S. AMELANG; M. NASH, Historia y género: las mujeres en la Europa moderna y contemporánea. Valencia, Alfonso el Magnánimo, 1990, 59-91. 
de súbdito- está estrechamente ligado al grupo de varones propietarios. Más aún, la ciudadanía legal y política ha estado limitada por la clase o grupo social, la renta, la raza y el sexo. Cuando Rousseau define el término citoyen se está refiriendo a un varón propietario y padre de familia: una familia sobre la cual ejerce una autoridad definida por el derecho y en virtud de la cual se regulan una serie de derechos y deberes ${ }^{\text {s. El concepto }}$ de ciudadanía lleva implícitas tres contradicciones fundamentales: individualismo/solidaridad; principio de igualdad/desigualdad de hecho; independencia como valor/experiencia de la dependencia. Aunque en teoría los ciudadanos sean semejantes, algunas diferencias y particularidades raciales, religiosas, sexuales, sociales- ponen en peligro su *ciudadanía*. La división social y sexual del trabajo y del poder; legitimada ampliamente en sus aspectos simbólicos, destruye la supuesta *universalidad" del concepto. La pobreza es un obstáculo para convertirse en ciudadano de pleno derecho. La estructura de género de la sociedad patriarcal, reforzada por el Código Napoleónico, define los comportamientos familiares como ‘relaciones entre varones, definidos como independientes económicamente, y mujeres, comprendidas y definidas como dependientes económicamente (y sobre todo obligados a serlo) (...) Esta preocupación ha permanecido incluso después de que las mujeres han podido acceder a la ciudadanía política (en el sentido de derecho al voto), puesto que en las otras esferas de actuación social siguen siendo consideradas primordialmente como dependientes de una renta masculina, y no, por tanto, como individuos con derecho a serlo. Esta dependencia de la otra parte sigue siendo la principal garantía de la unidad de la familia y, por consiguiente, de su funcionamiento ${ }^{6}$. La historia ha ignorado la trayectoria profesional de las mujeres propietarias (herederas solteras, viudas). ¿Ejercieron éstas de caciques o delegaron en sus parientes varones más próximos?. No hay que olvidar que el referente de la figura paterna era interiorizado en los procesos de socialización por mujeres y hombres, adoptando en las primeras un matiz de sumisión frente a las actitudes de emulación o rebelión de los segundos.

Por otra parte, todo cacique era en acto o en potencia un patrón capaz de establecer una red contractual en el mercado de trabajo, siguiendo las normas del sistema de producción vigente. Otra cosa es que el patrón delegue sus funciones en administradores y capataces, se dedique a la política, viaje por el mundo, pase su vida jugando a la ruleta o al tenis.

La legitimación religiosa presupone un adoctrinamiento realizado a través de diferentes vías, entre las cuales se encuentran la educación

(5) Véase CH. SARACENO, La estructura de género de la ciudadanía. En VV. AA., Mujery (6) Ibidem, p. 128. 
recibida en los colegios y en la familia, los folletos de propaganda, la prensa y otras lecturas, los sermones, las homilías, y más directamente, el confesionario. La dicotomía entre el bien y el mal parece impregnarlo todo. No hay que olvidar que la Iglesia constituye uno de los pilares ideológicos y sociológicos del caciquismo; su miedo al sufragio universal es el miedo que sienten las élites al igualitarismo, al socialismo, a la homogeneización social. El caciquismo como sistema moral es asumido, practicado, reproducido y legitimado por la Monarquía y la Iglesia, las dos grandes instituciones terrenales, siendo la segunda de ellas, además, supraterrenal. El caciquismo como sistema amoral de vida es contestado, criticado, cuestionado por instituciones como la Real Academia de Ciencias Políticas y Morales, los Ateneos de las principales ciudades españolas, la Real Academia de Medicina y otras sociedades científicas. Para estas instituciones el caciquismo era sinónimo de mancha y lacra, un desorden patológico del tejido social que había que combatir con diversos recursos. Este era el objetivo, al menos en teoría, de los diversos regeneracionismos surgidos en la España de entresiglos ${ }^{7}$. Su fracaso impidió erradicar la existencia, los modos, usos y costumbres de las oligarquías ecónomicas y políticas, que siguieron controlando los resortes de poder locales.

Esta renovación conceptual del caciquismo presupone también la necesidad de revisar la metodología utilizada por los historiadores.Es preciso subrayar las coincidencias que existen entre el poder económico y social y las clases políticas provinciales. En este sentido los "partidos de notables* constituyen las formas de legitimación de las estructuras caciquiles y son el canal de comunicación -sumamente imperfecto, desde luegoentre el ciudadano y el Estado. Hay que estudiar el funcionamiento teóri$\mathrm{co}$, a través de los estatutos y reglamentos, y el funcionamiento efectivo de las "asambleas" y comités provinciales, locales o de distrito, de las juntas ejecutivas y de las comisiones especiales. Los censos electorales y los archivos privados de políticos nacionales, regionales y locales ofrecen datos de interés que deben ser analizados desde una nueva perspectiva: la del estudio de la :clase política* a partir del análisis de los cargos públicos (Cortes, Diputaciones, Ayuntamientos), señalando la distribución socioprofesional y la endogamia de grupo. Por este motivo hay que revisar la correspondencia de Maura, Dato y Alba; examinar la de Fernández de Córdoba, Rivas y La Chica en Granada; la de Bergamín, Romero Robledo, Modesto Escovar Acosta y Gómez Chaix en Málaga. Para el periodo republicano y la guerra civil se pueden realizar entrevistas a los hombres y

(7) J. COSTA, Oligarquia y caciquismo, colectivismo agrario y otros escritos. Ed. y prólogo de R. Pérez de la Dehesa. Madrid, Alianza, 1969. J. MAURICE; C. SERRANO Joaquin Costa: Crisis de la Restauración y populismo (1875- 1911). Madrid. Siglo XXI, 1977. 
mujeres -relevantes o no- que vivieron en aquella época. Asímismo hay que descubrir las representaciones culturales, letradas e iletradas, del caciquismo y del padrinazgo en coplas, refranes, poemas, cuentos, leyendas, y también en la narrativa. La novela histórica, realista y naturalista, los folletines publicados en la prensa o que comenzaban a ser radiados en la Segunda República, las múltiples obras de la literatura militante y de combate, y en el terreno iconográfico los grabados y carteles, son fuentes dignas de ser utilizadas y, en muchos casos, reinterpretadas.

Para establecer las redes caciquiles hay que analizar la composición y el funcionamiento de las instituciones económicas de la España de la Restauración (Ligas de Contribuyentes, Cámaras de Comercio, Cámaras Agrarias, Compañías Mineras, entre otros organismos), el sistema de Administración de Justicia, el funcionamiento de las Juntas Electorales locales y provinciales -en clave de larga duración- tratando de ver la formación de los grupos de poder y cómo se reproducen éstos a través del tiempo. En este caso, la prosopografía o biografía colectiva nos aporta datos personales, económicos y políticos que resaltan la endogamia del grupo y la existencia de una élite de poder local.

Especial atención merece la trayectoria seguida por Ayuntamientos y Diputaciones. También es necesario confeccionar un censo de políticos y caciques.

Respecto a las líneas de trabajo hay que replantear el sufragio censitario universal masculino y la consecución del femenino desechando en este caso la teoría del "mal necesario* o del "mal menor, entre otras actitudes moralistas y culpabilizadoras ${ }^{8}$.

\section{EL CACIQUISMO EN ANDALUCÍA ORIENTAL. ESTADO DE LA CUESTION}

En este epígrafe trato de hacer una revisión de los trabajos que tienen como objeto de estudio el caciquismo en el periodo de la Restauración, en las provincias de Granada, Almería, Jaén y Málaga. Granada es la provincia que cuenta con más aportaciones sobre el tema, quizá porque hasta comienzos de los años setenta ha sido la única sede universitaria de Andalucía oriental, marcando la pauta en las investigaciones realizadas. No obstante, Málaga ha acortado distancias en los últimos años, y ello se ha traducido en numerosas investigaciones y, en algunos casos, en la difusión de propuestas de revisión conceptual y metodológica de determinados temas, entre ellos el del caciquismo.

(8) M.D. RAMOS, Luces y sombras en torno a una polémica: la concesión del sufragio femenino en España (1931-1933). Baetica (Mảlaga), núm. 11 (1987), 563-573. 
Tratando de sistematizar la exposición agruparé los trabajos siguiendo un criterio cronológico para ver cómo se cruzan los temas realizados sobre partidos políticos, dinámica electoral, caciquismo y ruptura del modelo caciquil. La perspectiva de análisis responde casi siempre a la visión clásica del problema (Tusell, Varela Ortega), adoptando como punto de referencia la obra de Tusell Oligarquía y caciquismo en Andalucía, 1890-1923, y sólo de un tiempo a esta parte se aprecian nuevos enfoques que en su momento irécomentando. Sin lugar a dudas el Congreso sobre Caciquismo y República en Andalucía servirá de revulsivo para la consolidación de estos nuevos trabajos.

Los orígenes de la Restauración y el poder conservador en Andalucía oriental -pese a la procedencia malagueña de Cánovas del Castillo- no ha merecido un interés excesivo a los ojos de los investigadores, que han preferido orientar sus trabajos hacia los partidos de oposición al turno canovista (republicanos y partido socialista), el anarquismo, o hacia la coyuntura aperturista marcada por el partido liberal en los años 18871891 (Ley de Asociaciones y del Jurado, ódigo Civil, sufragio universal masculino y su aplicación en las elecciones de 1891).

El libro de Antonio María Calero Movimientos sociales en Andalucía (1820-1936) sigue siendo un punto de referencia importante para tener una visión de conjunto y para estudiar el grado de implantación por provincias, la acción política y electoral y la conflictividad laboral de los socialistas andaluces en el periodo 1888-1923. No me ocuparé en este artículo de la oposición representada por anarquistas y anarcosindicalistas debido a su abstencionismo político y electoral. Retomar este tema, buscando la posible incidencia de ese abstencionismo en el desgaste del sistema caciquil, originaría un extenso tema monográfico.

Antonio Nadal ha escrito algunos artículos sobre los orígenes del partido socialista en Málaga y sobre la actitud que mantuvo ante las primeras elecciones por sufragio universal9; Cristóbal García Montoro ha aportado una interesante documentación sobre la agrupación socialista de Málaga en la fase de regresión y enquistamiento que siguió a la derrota de los trabajadores de .Industria Malagueña* en $1894^{10}$. Por mi parte, he intentado aproximarme a la figura del fundador del PSOE malagueño, Rafael Salinas, en mi libro Burgueses y proletarios malagueños. Lucha de clases en la crisis de la Restauración, 1914-1923. Salinas, que fracasó en su intento de organizar a los trabajadores agrícolas en

(9) A. NADAL, El Partido Socialista ante las primeras elecciones por sufragio universal en Málaga, 1891. Jábega n 17 (1977), 19-28.

(10) C. GARCIA MONTORO, Para una historia del asociacionismo obrero en Málaga: La Unión Social. Actas III Coloquio de Historia de Andalucía. Córdoba, marzo 1983. Historia Contemporánea. Tomo I. Córdoba, 1985, 367-376. 
1905 , se mostraba contrario al reparto y defensor de la socialización de los medios de producción y' cambio y de la apropiación individual del producto del trabajo, de ahí sus continuas escaramuzas con los anarquistas y con la "burguesía progresiva" representada por el partido federal -rival en el "mercado revolucionario*-, a la que aplicó el criterio de "clase contra clase* sostenido hasta 1909 por Pablo Iglesias ${ }^{11}$.

Para entender las bases socioeconómicas del caciquismo en Jaén, hay que acudir a las aportaciones de Gay Armenteros ${ }^{12}$, Salvador Hernández Armenteros ${ }^{13}$ y María Dolores Muñoz Dueñas, que ha estudiado el distrito minero de Linares en el periodo $1850-1881^{14}$. La tensión entre las oligarquías provinciales, las compañías mineras y los grupos de oposición ha sido minuciosamente analizada, en clave de larga duración, por Luís Garrido González en su libro Riqueza y tragedia social. Historia de la clase obrera en la provincia de Jaén (1820-1939).

Respecto al comportamiento sociopolítico de las burguesías y clases medias, Arcas Cubero en su libro El republicanismo malagueño durante la Restauración (1875-1973) ha realizado una aportación fundamental para conocer la génesis histórica de los grupos republicanos que conformaron la oposición al sistema canovista. Según este autor, tuvo que producirse el relevo generacional y el fracaso de las tentativas de crear un partido nacional para que surgiera en Málaga una plataforma republicana unitaria que acabó controlando el poder municipal en el periodo 1909-1915. El reformismo republicano logró el apoyo de los trabajadores en cuestiones como los consumos o la campaña contra Maura pero en otros asuntos, como el de las subsistencias, se quedó a medio camino o visiblemente atrás, temeroso de ser desbordado por la izquierda ${ }^{15}$. Es significativo, por otra parte, que algunos de sus líderes -entre ellos Pedro Gómez Chaix en Málaga- se dejaran encasillar por el Ministerio de la Gobernación, entrando a formar parte del entramado caciquil contra el que tantas veces habían clamado, clamaban y clamarían. Muy similar, por el tema y el enfoque, es el trabajo de Fernando López Martín $E l$ republicanismo almeriense durante la Restauración, tesis doctoral leída en la universidad de Granada en 1986.

(11) R. SALINAS, Obligado por la burguesia. Málaga, 1902.

(12) J.C. GAY ARMENTEROS, Jaén entre dos siglos. Las bases materiales y sociales. Córdoba, Instituto de Historia de Andalucía, 1978.

(13) S. HERNANDEZ ARMENTEROS, Jaén ante la II República. Bases económicas, sociales y políticas de una transición. Granada, Universidad, 1988.

(14) M. D. MUÑOZ DUEÑAS, Importancia del factor tecnológico en el crecimiento económiCo, del distrito minero de Linares, 1850-1881. Actas I Congreso de Historia de Andalucía. Córdoba, M.P.C.A., 1979, vol. I, 401-430.

(15) F. ARCAS CUBERO, El republicanismo malagueño durante la Restauración. Córdoba, Ayuntamiento, 1985. 
Planteada también con un esquema de larga duración, la tesis de Dolores Jiménez Martínez Un contexto adecuado al funcionamiento caciquil. El distrito de Purchena (Almería), 1875-1923 estudia las deficiencias de esta comarca rural, y más concretamente el aislamiento, las escasas vías de comunicación, la crisis agraria, la fuerte emigración y el bajo nivel cultural, antes de pasar al estudio del comportamiento electoral de la población. Subraya la autora las bases económicas y sociales del caciquismo, prestando especial atención a la minería del hierro de Serón de Bacares y las canteras de mármol de Macael, y aproximándose a las realidades del movimiento obrero.

El libro de Francisco Crespillo Carregalo Elecciones y partidos políticos en Málaga (1890-1901) tiene puntos en común con el trabajo de María Jesús Merinero Comportamiento político de Cáceres, 1891-1931, el de F. Peña Gallego Elecciones legislativas en la provincia de Alicante durante la época de la Restauración (1875-1902) y el de Tomás Peláez Peláez Elecciones en Granada, 1900-1914. Crespillo Carregalo analiza en primer lugar las elecciones de 1891 , y aplica a esas y a las que le siguieron un esquema *clásico* en el que se contemplan los partidos en presencia, el desarrollo de la campaña electoral, la actuación gubernamental y la evidencia del encasillado, los resultados electorales, los análisis postelectorales y las críticas al sistema, para acabar con unas conclusiones.

El libro de F.R. González Caciques, burgueses y campesinos. Loja, 1900-192317 aborda el estudio del caciquismo en sus formas políticoelectoral y económica-administrativa. Una novedad, ya que la mayor parte de los estudios han sido realizados desde el primer punto de vista. $\mathrm{Al}$ análisis de los grupos políticos (conservador y liberal) une el autor el de las sociedades patronales, tema que me parece especialmente interesante para entender las redes caciquiles.

Rafael y Ricardo Ruiz Pérez son los autores del libro Propiedad de la tierra y caciquismo (El caso de Dólar en tiempos de Alfonso XIII), en el que el problema de la tierra sirve de introducción al estudio del caciquismo político-electoral y administrativo durante el periodo 1899-1918.

En la investigación de Tomás Peláez Huertas Elecciones en Granada, 1900-1914 ${ }^{1}$ se analizan las elecciones de 1901, 1903, 1905, 1907, 1910 y 1914, con el fin de averiguar si las corrientes regenera cionistas de la España de entresiglos lograron erradicar o al menos atajar los compor-

(16) F. CRESPILLO CARREGALO, Elecciones y partidos políticos en Málaga (1890-1901). Málaga, Diputación Provincial, 1990.

(17) F.R. GONZALEZ, Caciques, burgueses y campesinos. Loja, 1900-1923. Loja, Ayuntamiento, 1986.

(18) T. PELAEZ HUERTAS, Elecciones en Granada, 1900-1914. Memoria de Licenciatura mecanografiada. Granada, Facultad de Filosofía y Letras, s.a. 
tamientos caciquiles. Como es sabido, Maura quiso acabar con la corrupción en 1903, Montero Ríos fracasó en el intento cambiar la legislación en 1905 y fue finalmente Maura quien promulgó una nueva ley electoral en 1907. Aunque en las ciudades resultaba más fácil la movilización política del electorado, en los distritos la violencia surgía en los días previos a la votación y adoptaba la forma de escopetazos, detenciones y rotura de urnas. En los agregados era más fácil el fraude electoral, por eso los candidatos encasillados sacaban en ellos los votos necesarios para cerrar la victoria a los republicanos. No obstante en ocasiones se producía la ruptura del modelo. Asíocurrió en 1903 con el candidato republicano Leonardo Ortega que salió diputado después de vencer múltiples dificultades. El regeneracionismo no acabó con el caciquismo. Todo quedó en una simple denuncia de las corrupciones por parte de la prensa y de los políticos, que criticaban el sistema cuando estaban en la oposición pero una vez en el poder se contagiaban de aquello que decían combatir.

Insisto en que se debe dar la vuelta a ciertos planteamientos, ya que el dirigismo, la dependencia, la desmovilización política y la existencia de una "masa neutra" no son únicamente la base del caciquismo sino que constituyen el efecto de un fenómeno que rebasa los comportamientos políticos para instalarse en la vida cotidiana. El cacique es el padrino* al que acude el pueblo para pedirle favores de forma individual o general.

Luís González Ruiz es autor del trabajo titulado La Liga Agraria y los problemas de la agricultura granadina a finales del siglo XIX (1887-1901 ${ }^{19}$. Entre los objetivos de este grupo de presión sobresalen la obtención de un sistema impositivo que no gravase a los agricultores, la condena del fraude fiscal, la rebaja de las contribuciones rústicas, la reclamación de nuevos cultivos como el tabaco y la lucha contra la inmoralidad administrativa.

La Liga, que se definía como apolítica e independiente, se convertirá, en 1901, en la Cámara Oficial Agraria de Granada, impulsada, entre otros próceres, por el marqués de Dilar, un idealista conservador, firme defensor de los valores tradicionales e introductor del tabaco en la vega granadina.

Los apéndices del trabajo -la relación de las Juntas Directivas y una Memoria de la Liga Agraria-, permitirían hacer un estudio prosopográfico de estos prohombres granadinos. Eran, con toda seguridad, algunos de los "padres de la patria".

Realizada desde un punto de vista diferente, la investigación de Manuel Serrano Aguilera Antecedentes del regeneracionismo en Granada: aspectos culturales, $1880-1902^{20}$ nos muestra la existencia de una élite

(19) L. GONZALEZ RUIZ, La Liga Agraria y los problemas de la agricultura granadina a finales del siglo XIX (1887-1901). Granada, Facultad de Filosofía y Letras, 1988.

(20) M. SERRANO AGUILERA, Antecedentes del regeneracionismo en Granada: aspectos culturales, 1880-1902. Granada, Facultad de Filosofía y Letras, 1988. 
intelectual encabezada por Ganivet y convencida de que el renacimiento de la ciudad vendría a través de la cultura. No hay que olvidar que durante esos años había surgido en Andalucía un brote regionalista entendido como vía de regeneración cultural, cuyo núcleo, en Granada, fue el propio Ganivet y el Grupo del Avellano. Los Juegos Florales de Sevilla y la Sociedad Malagueña de Çiencias, que tuteló la revista Andalucia Cientifica, son otras muestras de ese brote regionalista ${ }^{21}$. En Granada las Colonias Escolares, las Escuelas del Ave María, la obra de regeneración de la Universidad, la Sociedad Económica de Amigos del País, el Liceo Artístico y Literario, el Centro Artístico, la Sociedad HispanoMauritana y el Ateneo Científico y Literario hicieron el resto. La Exposición Bibliográfica de 1888 y los Juegos Florales de 1897 fueron dos hitos importantes en esa labor cultural.

De gran importancia para entender el funcionamiento de las redes caciquiles es el trabajo de Juan José Díaz Aznarte Introducción al estudio de los padrones municipales. La estructura socioprofesional de Granada en $1900^{22}$, en el que se analizan exhaustivamente la demografía, las actividades laborales, la educación, la estructura familiar y la vivienda, variables que están en la base de la articulación del sistema económico y del sistema de poder.

Historiográficamente, hay etapas y temas con una estimable cobertura investigadora, como acabamos de ver, y zonas se sombra que conviene clarificar, por ejemplo la sociología y la geografía política y la evolución de los partidos del turno y de la oposición en los años de la preguerra europea. En Málaga el artículo de José Velasco Gómez Elecciones municipales en Málaga, 1909-1911-191323 y sobre todo el amplio eśtudio de Arcas Cubero sobre el republicanismo ${ }^{24}$ sitúan la crisis de 1909 y sus consecuencias políticas y electorales: conjunción republicano-socialista, constitución de la "República Municipal" malagueña, ruptura del modelo caciquil en algunas localidades. Lo acontecido en 1909 y en años sucesivos en Granada fue investigado también por Antonio María Calero en su Historia del movimiento obrero en Granada ${ }^{25}$. Yo misma me ocupé de estudiar la ruptura del modelo caciquil en Benagalbón en el transcurso de las elecciones generales

(21) M.D. RAMOS; J. L. CARRILLO; J. CASTELLANOS, Regeneracionismo, regionalismo y ciencia en la Málaga de comienzos de siglo: la revista *Andalucía Científica. (1903-1904). Dynamis (Universidad de Granada), vols. 5-6 (1985-1986), 307-341.

(22) J.J. DIAZ AZNARTE, Introducción al estudio de los padrones municipales. La estructura socioprofesional de Granada en 1900. Granada, Facultad de Filosofía y Letras, 1988.

(23) J. VEL.ASCO GOMEZ, Elecciones municipales en Málaga, 1909-1911-1913. Jábega nª 30 (1980), 57-63.

(24) F. ARCAS CUBERO, op. cit. (nota 15)

(25) A. M. CALERO, Historia del movimiento obrero en Granada (1909-1923). Madrid, Tecnos, 1973. 
de $1914^{26}$ y de replantear los acontecimientos de 1917 a la luz de la teoría del poder en mi libro La crisis de 1917 en Málaga ${ }^{27}$. Este fue el punto de partida de un análisis más amplio sobre poder e ideologías en la encrucijada de 1914-1923, realizado a través del estudio de los partidos políticos y de la confrontación de los bloques sociales, y mostrando la articulación del sistema económico y del sistema de poder ${ }^{28}$. Lo acontecido en Jaén, con una especial referencia a la crisis de 1917, ha sido estudiado por Tuñón de $\mathrm{Lara}^{29}$, Luís Garrido ${ }^{30}$ y F. Zaragoza, que ha estudiado las repercusiones de esta crisis en la vida municipal jiennense ${ }^{31}$. El trabajo de Fernando Martínez Lópéz nos ayuda a establecer lo sucedido en Almería ${ }^{32}$.

El libro de Mario López Martínez Granada, 1930-1931. De la Dictadura a la República nos muestra, en la primera parte, la génesis y evolución de la Dictadura en Granada. Su autor, al analizar lo ocurrido en esta ciudad entre 1919 y 1923, nos dice: "No fue sólo una lucha contra la corrupción, sino también un conflicto encarnizado por trasvasar el poder de unas familias a otras. Esto sólo se puede entender en un régimen oligárquico como el de la crisis de la Restauración, cuya política de tutela sobre el cuerpo social, su idea de poder como un bien patrimonial y el traducir el conflicto político como una lucha personal y no ideológica, pueden desentrañar una buena parte de la espesa madeja de aquella crisis ${ }^{33}$. Otros aspectos de la Dictadura han sido estudiados por Fernando Martínez López en su Memoria de Licenciatura El corporativismo en la Dictadura de Primo de Rivera. Su aplicación en Granada (1923-1930). Su autor concede especial atención a los distintos aspectos de esta ideología, a su implantación en Europa y al estudio de los antecedentes corporativos en España, destacando la creación del Comité Paritario antes de que surgiera la Organización Corporativa Nacional. Así mismo, estudia la organización corporativista en Granada.

(26) M.D. RAMOS, op. cit. (nota 2).

(27) M.D. RAMOS, La crisis de 1917 en Málaga. Málaga, Diputación Provincial, 1987.

(28) M.D. RAMOS, Burgueses y proletarios malagueños. Lucha de clases en la crisis de la Restauración (1914-1923). Córdoba, Ayuntamiento, 1990.

(29) M. TUÑON DE LARA, Jaén en la coyuntura conflictiva, 1917-1920. En Luchas obreras y campesinas en la Andalucia del siglo XX. Jaén (1917-1920); Sevilla (1930-1932). Madrid, Siglo XXI, 1978, 7-121.

(30) L. GARRIDO GONZALEZ, Riqueza y tragedia social. Historia de la clase obrera en la provincia de Jaén (1820-1939). Jaén, Diputación Provincial, 2 vols., 1990.

(31) F. ZARAGOZA, La crisis del canovismo en la vida municipal jiennense (1917-1923). Actas I Congreso de Historia de Andalucia. Diciembre 1976. Andalucía Contemporánea (siglos XIX y XX). Córdoba, MPCA, 1979, vol. II, 575-582.

(32) F. MARTINEZ LOPEZ, El republicanismo almeriense durante la Restauración (18751923). Tesis doctoral mecanografiada. Granada, Facultad de Filosofía y Letras, 1986.

(33) M. LOPEZ MARTINEZ, Granada (1930-1931). De la Dictadura a la República. Granada, Ediciones TAT, 1990. 
Sin duda el caciquismo pervivió en la dictadura de Primo de Rivera apoyándose en aparatos de control social muy concretos, como la Unión Patriótica y el Somatén, fundado en Granada en 1923. El fracaso de la regeneración política anunciada por el dictador cuenta con numerosos indicadores: el problema agrario siguió vigente, las oligarquías políticas no se sanearon y los caciques continuaron controlando los resortes de poder local.

En Málaga, la dictadura de Primo de Rivera es objeto de estudio actualmente en la tesis doctoral de María José González Castillejo y la transición a la República ha sido abordada por Nadal Sánchez ${ }^{34}$.

¿Cuáles son las líneas de investigación en la actualidad?, ¿qué enfoques prevalecen?, iexisten nuevas interpretaciones sobre el caciquismo?. En las comunicaciones remitidas al Congreso Caciquismo y República en Andalucía se observa, por un lado, un continuado interés por el estudio de los partidos, la normativa y la dinámica electoral, y por otro el desplazamiento de ese interés hacia cuestiones "más novedosas", entre las que se cuenta el estudio de las redes caciquiles desde una perspectiva no estrictamente "política»; el análisis de una sociedad clasista y endogámica que posibilita las prácticas caciquiles; los vínculos existentes entre los grupos de notables conservadores y liberales y los casinos y sociedades recreativas de las agrociudades y pueblos andaluces, hasta el punto que la política seguida por los respectivos Cabildos municipales responde claramente a los intereses de estas oligarquías constituidas por propietarios de tierras, industriales, comerciantes y profesionales; el estudio de la composición social del electorado y sus repercusiones sobre la violencia política; el poder de la prensa en el mantenimiento de las redes caciquiles, al concentrar un grupo de grandes familias la propiedad de los medios de comunicación; la relación entre justicia municipal y caciquismo, relación en la que la naturaleza del cargo no puede desvincularse de la red clientelar y en la que, además, éste se utiliza como un arma política en la vida local; la revisión de determinados líderes políticos (Burgos y Mazo, Ramón de Carranza, José Díaz); el papel político de las grandes empresas y las compañías mineras; la pervivencia de las prácticas caciquiles tras la llegada de la Segunda República.

En la sección dedicada a Andalucía oriental en tiempos de la Restauración se presentaron cuatro comunicaciones. El equipo formado por Salvador Cruz Artacho, David Martínez López y Manuel Martínez Martín remitió dos trabajos. En el primero de ellos, Procesos electorales y mecanismos de control político: la composición social del cuerpo electoral gra-

(34) A. NADAL SANCHEZ, Andalucia ante el advenimiento de la Repiblica. Coyuntura política y movimientos huelguísticos en la Málaga de 1903. Málaga, Departamento de Historia Contemporánea, 1981. 
nadino basta la promulgación del sufragio universal masculino, se propone una revisión de los estudios de sociología electoral. Como afirman sus autores: "Buena parte de esta historiografía laboral se caracterizará por los estudios centrados sobre aspectos básicamente políticos -donde las variantes, las estructuras socioeconómicas no son sacadas a relucir a la hora de elaborar una teoría explicativa de la realidad pública nacional durante ese periodo-, y donde el fenómeno del fraude electoral viene a ser explicado en función de factores internos e inmersos en el propio sistema político ${ }^{35}$. El ámbito geográfico abarca cuatro núcleos urbanos: Granada, Montefrio, Motril y Santa Fe, representativos de todo el territorio granadino. Al contraponerlos surgen dos modelos distintos: uno de carácter rural que engloba los municipios de Montefrío, Motril y Santa Fe, y otro de carácter urbano en la ciudad de Granada y alrededores. Esa dualidad se ve reflejada también en la estructura socio-profesional de las personas con derecho a sufragio. La mayor parte de los electores ocupa un lugar de dependencia en las relaciones sociales de producción, lo que determinará su modo de vida y también sus comportamientos políticoelectorales. Esta situación se ve un poco más matizada en la ciudad de Granada debido a su carácter urbano.

En la comunicación La propiedad de la tierra como fuente del poder local. Santa Fe entre el voto censitario y el sufragio universal, Manuel Martínez Martín, David Martínez López y Salvador Cruz Artacho pretenden articular la estructura política y socioeconómica del citado municipio en el transcurso de la Restauración. En primer lugar analizan la propiedad y explotación de la tierra como base del poder local durante la segunda mitad del siglo XIX -es la hipótesis "ascendente" a la hora de explicar la articulación entre realidades socioeconómicas y políticas-, prestando especial atención al proceso de consolidación de la burguesía agraria y a la incidencia de la crisis de la remolacha azucarera entre 1887 y 1892 . En la segunda parte el objeto de estudio es la estructura de poder local antes y después de la instauración del sufragio universal masculino, que tiene lugar precisamente durante la coyuntura de crisis económica de la remolacha azucarera. La extensión del sufragio supuso una ampliación del cuerpo electoral importante -hasta un $27 \%$ de la población-pero ni alteró la composición de la élite de poder de Santa Fe, cuyos miembros son legitimados a partir de entonces con un mayor número de votos.

Las restantes comunicaciones tratan de establecer las conexiones de la prensa con las estructuras de poder. Antonio Checa Godoy en el trabajo Políticos y periodistas. Apuntes sobre el poder en el Motril contemporáneo pone de relieve cómo el periodismo está al servicio de los grupos domi-

(35)Véase la comunicación que se reproduce en estas actas. 
nantes, especialmente durante la Restauración. En Motril, que pasó tras un breve periodo de indefinición del ciclo del algodón al de la caña de azúcar, las actuaciones caciquiles eran frecuentes y provocaban de vez en cuando estallidos de protesta. Aunque en 1885 la economía era pujante, esta tendencia sufrirá una inflexión una década más tarde como consecuencia de la crisis de la caña de azúcar y este hecho tendrá importantes repercusiones demográficas (estancamiento de la población, emigraciones). En un marco de docilidad electoral a los gobiernos de turno, los grandes propietarios se sirven de dos importantes mecanismos: los alcaldes, meros hombres de paja, cuando no pertenecen a las propias familias dominantes, y los periódicos, que son dirigidos en muchas ocasiones por los antiguos alcaldes, lo que daría pie a situaciones sumamente pintorescas: 'Títulos que nacen para aupar a una persona o, por el contrario, para derribar a un alcalde; periodistas que alaban la libertad de expresión cuando redactan periódicos, pero persiguen a los colegas hostiles cuando son la autoridad local. Nunca, ni antes ni después de la Restauración, veremos tan estrecha vinculación entre el poder político y la prensa ${ }^{36}$. Verdaderamente la prensa se había erigido ya en el cuarto poder.

Por último, la comunicación de Juan Antonio García Galindo Caciquismo y prensa en España: las convulsas relaciones de periodistas y politicos a finales del siglo XIX. El caso del periodista malagueño Francisco de Asís García Peláez (1891-1899) es un buen ejemplo de historia narrativa. En ella se cuenta el "martirologion de García Peláez, inculpado del asesinato del concejal electo de la ciudad de Málaga, Manuel Loring Heredia, hermano político del Francisco Silvela, a la sazón ministro de la Gobernación. Los hechos no quedaron claros del todo, lo que unido a la personalidad de la víctima y a las consecuencias que tuvo para el supuesto agresor -tras ser indultado en 1898 murió un año después camino del destierro, en la travesía hacia Nueva York- convirtieron el caso en un verdadero escándalo político. En realidad estaríamos ante una crónica negra, una más, si no fuera por el trasfondo del asunto: la denuncia en El Diario Mercantil, propiedad de la familia del periodista García Peláez, de la malversación de fondos cometida contra un grupo de clientes de la Caja de Ahorros y Monte de Piedad. Entre los implicados figuraban amigos y parientes del concejal Loring Heredia, quien al parecer provocóa García Peláez poco antes de producirse la discusión que acabó de forma tan dramática.

En esta historia tenemos una constatación cualitativa, externa, no política, de los pliegues y revueltas de los comportamientos caciquiles.

(36) Véase la comunicación de Checa Godoy reproducida en estas actas. Cf. de este autor Historia de la prensa jiennense (1808-1983). Jaén, Diputación Provincial, 1986. 